\title{
Engineering Properties of Ternary Cementless Blended Materials
}

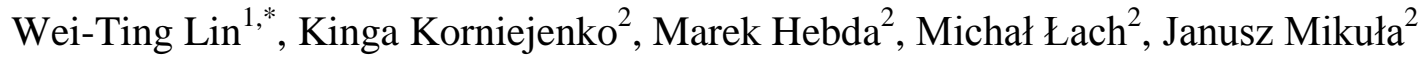 \\ ${ }^{1}$ Department of Civil Engineering, National Ilan University, Yilan, Taiwan \\ ${ }^{2}$ Institute of Materials Engineering, Faculty of Materials Engineering and Physics, \\ Cracow University of Technology, Kraków, Poland \\ Received 23 January 2020; received in revised form 15 April 2020; accepted 08 June 2020 \\ DOI: https://doi.org/10.46604/ijeti.2020.5201
}

\begin{abstract}
This study combined three by-products to fully replace cement as cementless blended materials without the need for an alkali activator. The feasibility of the cementless materials was assessed in terms of workability, mechanical properties, permeability, and microscopic properties. An innovation cementless blended material is consisted of desulfurized gypsum, water-quenched blast-furnace slag, and co-fired fly ash, resulting in a ternary mixture. The results were shown to perform well in terms of compressive strength, absorption, and chloride ion penetration. Scanning electron microscopic micrographs revealed that desulfurized gypsum accelerated hardening and improved the compressive strength through the formation of C-S-H and C-A-S-H gels produced by $\mathrm{Ca}(\mathrm{OH})_{2}$, $\mathrm{SiO}_{2}$, and $\mathrm{Al}_{2} \mathrm{O}_{3}$. The improvements in permeability can be attributed to the coating of gypsum particles by hydration products. Overall, our results confirm the efficacy of combining 3\% gypsum, $60 \%$ slag, and $37 \%$ fly ash as the cementless composites with excellent strength and permeability.
\end{abstract}

Keywords: non-cement binder, co-fired fly ash, GGBS, chloride migration, green materials

\section{Introduction}

The enormous quantity of $\mathrm{CO}_{2}$ produced in the manufacture of cement has prompted efforts to develop green alternatives [1]. Much of this work has focused on the use of fly ash, ground-granulated blast-furnace slag (ggbs), and/or silica fume as a partial replacement for cement, referred to as supplementary cementitious materials [2-4]. At present, construction regulations in many countries stipulate an upper limit on the use of these materials; however, researchers continue efforts to develop new materials that could completely replace cement in civil construction. Alkali-activated cementless composites (AAC) and geopolymer are currently the main focus of this research [5-7]. AAC and geopolymers use fly ash, ggbs, and other supplementary cementitious materials (or their by-products) presenting pozzolanic activity [8-9]. Cementless composites are combined with a sodium/silicate-based alkali activator to promote the activation of AAC or the geopolymer. AAC provides good mechanical properties and excellent durability [10-13]; however, the need for of alkali activator greatly increases the overall cost.

Researchers have shown that using fly ash and slag as a partial or full replacement for Portland cement can immobilize lead and other toxic elements [14-15]. In several countries, these materials have also been used to make bricks and other non-structural elements for construction [16-17]. Nonetheless, there is a pressing need to find other suitable uses for these materials to reduce the cost of reprocessing, avoid the construction of large landfills, and conserve raw materials [18-20].

Taiwan, Korea, and Japan have recently begun developing cementless construction materials which do not impose high energy consumption. Researchers have demonstrated that ggbs can be combined with supplementary cementitious materials to 
create materials with compressive strength and durability sufficient for civil construction (30 MPa to $60 \mathrm{MPa}$ ) without the need for an added alkali activator [21-25]. Cementless blended materials containing ggbs and circulating-fluidized-bed (CFB) co-fired fly ash have been shown to form strong cementitious materials via hydration reactions without the addition of an alkali activator. These materials have been used to make CLSM, pervious concrete, and RCC [25-28]. The objective in this study was to combine ggbs and co-fired fly ash with desulfurized gypsum to create a novel cementless material for construction. Various combinations of desulfurized gypsum, water-quenched blast-furnace slag, and co-fired fly ash from circulation of fluidized bed combustion were assessed in terms of flowability, compressive strength, absorption, total charge-passed (rapid chloride permeability), chloride diffusion coefficient (accelerated chloride migration), and scanning electron microscopic (SEM) observations. A flowchart of the research methodology is presented in Fig. 1.

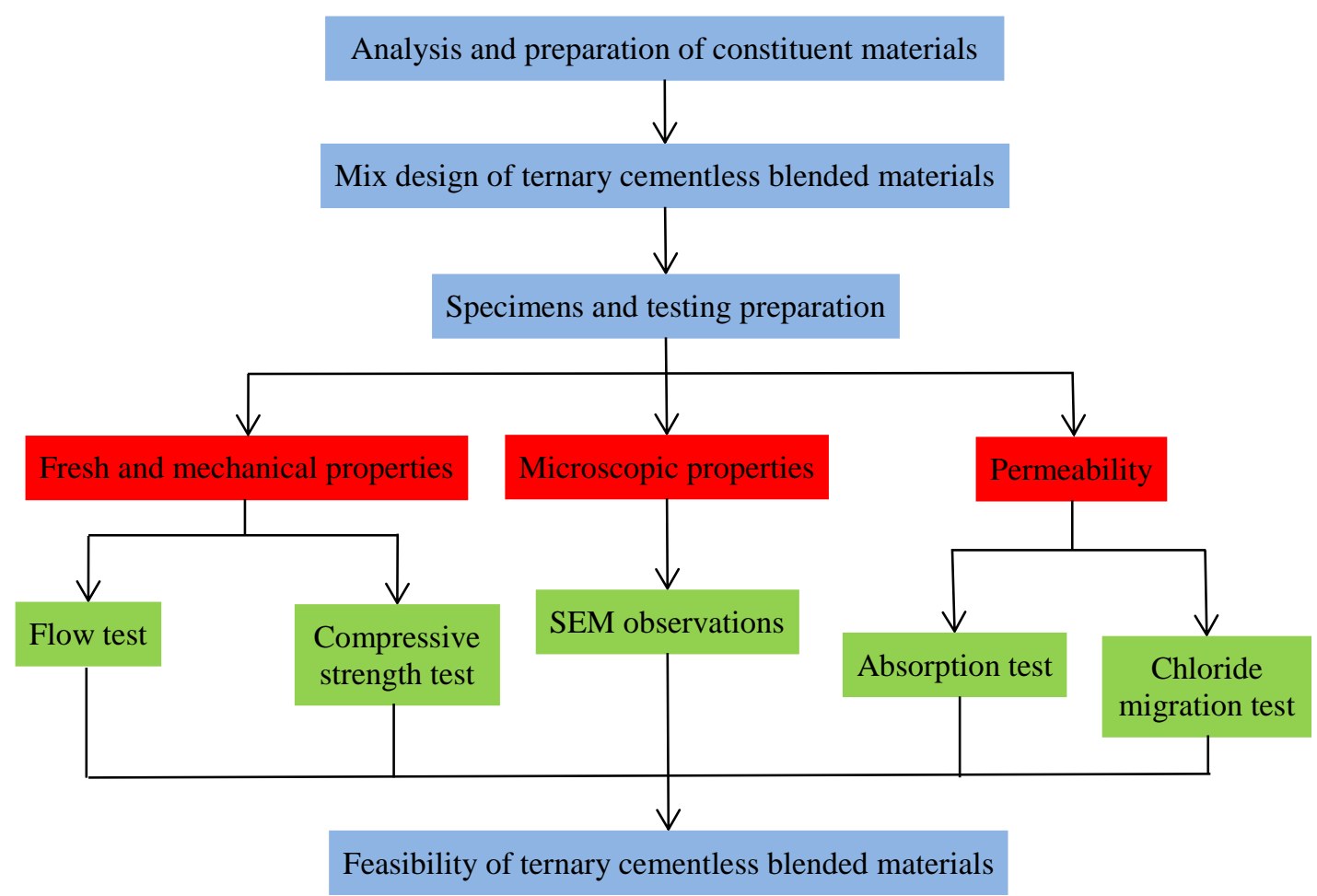

Fig. 1 Flowchart of research methodology

\section{Materials and Methods}

\subsection{Materials}

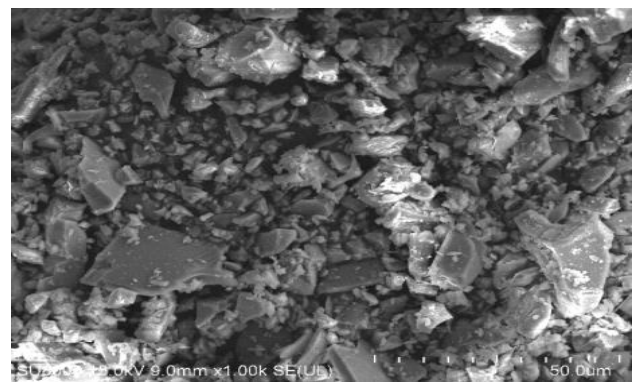

(a) ggbs

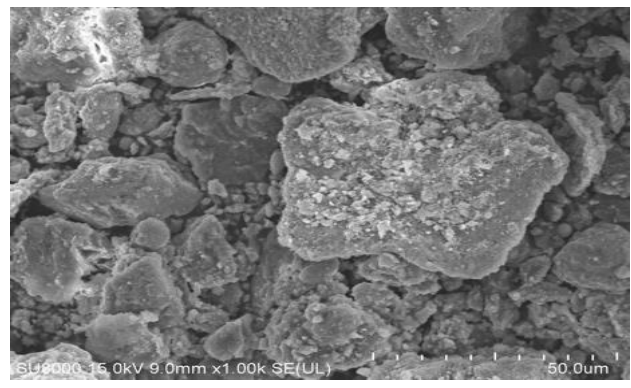

(b) $\mathrm{CFB}$

Fig. 2 SEM images of ggbs and co-fired fly ash

The ternary cementless blended material introduced in this paper combined ggbs, CFB co-fired fly ash, and desulfurized gypsum as an alternative to Portland cement. The first step involved screening the above combined materials through a No. 100 sieve $(150 \mu \mathrm{m})$. The ggbs (CHC Resources Corporation, Taiwan) had a fineness of $5860 \mathrm{~cm}^{2} / \mathrm{g}$ and specific gravity of 2.88 . The CFB co-fired fly ash (Yuen Foong Yu Corporation, Taiwan) had a fineness of $3000 \mathrm{~cm}^{2} / \mathrm{g}$ and specific gravity of 2.73 . The 
desulfurized gypsum (Sing Da thermal power plant, Taiwan) had a fineness of $2300 \mathrm{~cm}^{2} / \mathrm{g}$ and specific gravity of 2.59. Figs. 2(a)-2(b) respectively present SEM images of the ggbs and CFB co-fired fly ash [27]. As shown in Table 1, the chemical composition of both materials met the requirements of ASTM C989.

Table 1 Chemical composition of by-products

\begin{tabular}{|c|c|c|c|c|c|c|c|}
\hline \multirow{2}{*}{ Materials } & \multicolumn{7}{|c|}{ Chemical composition } \\
\cline { 2 - 8 } & $\mathrm{SiO}_{2}(\%)$ & $\mathrm{Al}_{2} \mathrm{O}_{3}(\%)$ & $\mathrm{Fe}_{2} \mathrm{O}_{3}(\%)$ & $\mathrm{CaO}(\%)$ & $\mathrm{MgO}(\%)$ & $\mathrm{SO}_{3}(\%)$ & others \\
\hline ggbs & 33.68 & 14.37 & 0.29 & 40.24 & 7.83 & 0.66 & 2.93 \\
\hline co-fired fly ash & 29.47 & 19.27 & 3.49 & 35.54 & 1.82 & 7.36 & 3.05 \\
\hline desulfurized gypsum & 3.44 & 0.98 & 0.15 & 67.90 & 0.67 & 10.15 & 16.71 \\
\hline
\end{tabular}

\subsection{Mix design and test methods}

Table 2 Mix design $\left(\mathrm{kg} / \mathrm{m}^{3}\right)$

\begin{tabular}{|c|c|c|c|c|c|c|}
\hline Mix no. & ggbs & desulfurized gypsum & CFB co-fired fly ash & fine aggregates & water & superplasticizers \\
\hline G50D1 & 262 & 5.3 & 257 & \multirow{6}{*}{1456} & \multirow{3}{*}{280.7} & 10.6 \\
\hline G50D3 & 262 & 15.9 & 246 & & & 10.6 \\
\hline G50D5 & 262 & 26.4 & 236 & & & 10.6 \\
\hline G60D1 & 318 & 5.3 & 206 & & \multirow{3}{*}{283.3} & 8.0 \\
\hline G60D3 & 318 & 15.9 & 196 & & & 8.0 \\
\hline G60D5 & 318 & 26.4 & 185 & & & 8.0 \\
\hline
\end{tabular}

In accordance with ASTM C109 specifications, the water/blender ratio (w/b) of the mortar specimens was maintained at at 0.55 , and the mass ratio of the blender/fine aggregates was 1:2.75. Table 2 lists all of the mix designs used in this study. Superplasticizers were used in accordance with ASTM C494 standards for Type F mixes. The specimens were numbered using letters and numbers to indicate the composition of the blended materials, where $\mathrm{G}$ indicates ggbs, D indicates desulfurized gypsum, and the following number indicates the percentage in the mix. For example, G50 denotes 50\% ggbs and D1 denotes $1 \%$ gypsum. Note however that ternary cementless blended materials also included a large quantity of fly ash. Thus, specimens labeled G50D3 included 50\% ggbs and 3\% desulfurized gypsum with the remaining 47\% made up of CFB co-fired fly ash. Table 3 presents the test methods, the dimensions of the specimens, and the standards referenced in this study. The setting time test was conducted using a Vicat Needle device and flow tests were conducted using a flow table in accordance with ASTM C230. Compressive strength was measured using a universal testing machine (SHIMADZU UH-1000). Particles were characterized using SEM (JSM-IT100) observation. Water absorption and non-steady-state chloride migration were tested using proprietary devices, the latter of which is shown in Fig. 3.

Table 3 Test methods

\begin{tabular}{|c|c|c|c|}
\hline \multirow{2}{*}{ Test methods } & Specimen dimensions (mm) & Referenced standard \\
\cline { 2 - 4 } Fresh properties & Setting time test & - & ASTM C191 \\
\hline Mechanical properties & Flow test & - & ASTM C1437 \\
\hline \multirow{2}{*}{ Permeability } & Compressive strength test & $50 \times 50 \times 50$ & ASTM C109 \\
\cline { 2 - 4 } & Absorption & $50 \times 50 \times 50$ & ASTM C642 \\
\hline Micro-structure observation & Non-steady-state chloride migration test & $\phi 100 \times 50$ & NT Build 492 \\
\hline
\end{tabular}

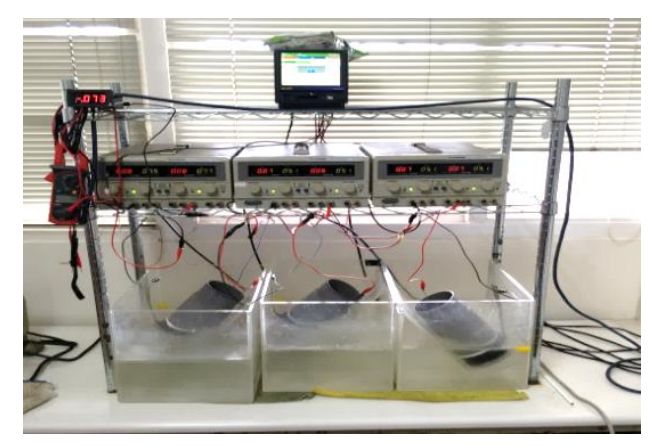

Fig. 3 Device used for non-steady-state chloride migration test 


\section{Results and Discussion}

\subsection{Fresh properties}

The fresh properties of the ternary cementless blended materials were evaluated in terms of setting time and flowability. Note that setting time included the initial setting time and final setting time, as summarized in Table 4. Under fixed dosage of slag ( $60 \%$ of the cementless blended materials), the addition of desulfurized gypsum greatly decreased the setting time. The lowest setting time (30 min) was observed in the G60D10 specimens. The dosage of desulfurized gypsum was proportional to the formation of C-S-H gel, and the mixes containing desulfurized gypsum also produced larger quantities of ettringite. Note that the ettringite and $\mathrm{C}_{3} \mathrm{~A}$ dissolved to form monosulfoaluminate and/or hydroxy-AFm phases immediately after the depletion of the gypsum [29-30].

Table 4 Setting times of G60 mixes

\begin{tabular}{|c|c|c|}
\hline Mix no. & Initial setting time (min) & Final setting time (min) \\
\hline G60 & 723 & 976 \\
\hline G60D2 & 200 & 575 \\
\hline G60D5 & 52 & 80 \\
\hline G60D7 & 34 & 53 \\
\hline G60D10 & 15 & 30 \\
\hline
\end{tabular}

The G60 specimens easily met the $110 \%$ flowability standard; however, the G50 specimens were unable to do so without a larger quantity of added superplasticizer. Table 5 lists the flowability results obtained for the three G60 specimens. The addition of desulphurized gypsum was shown not to have significant effect on the fluidity of the mix.

Table 5 Flow test results of G60 mixes

\begin{tabular}{|c|c|c|c|}
\hline \multirow{2}{*}{ Testing no. } & \multicolumn{3}{|c|}{ Mix no. } \\
\cline { 2 - 4 } & G60D1 & G60D2 & G60D3 \\
\hline 1 & 21.5 & 21.5 & 21.6 \\
\hline 2 & 21.3 & 21.0 & 21.8 \\
\hline 3 & 21.8 & 20.6 & 21.8 \\
\hline 4 & 21.5 & 21.3 & 21.6 \\
\hline Ave. & 21.5 & 21.1 & 21.7 \\
\hline Flowability (\%) & 115 & 111 & 117 \\
\hline
\end{tabular}

\subsection{Compressive strength}

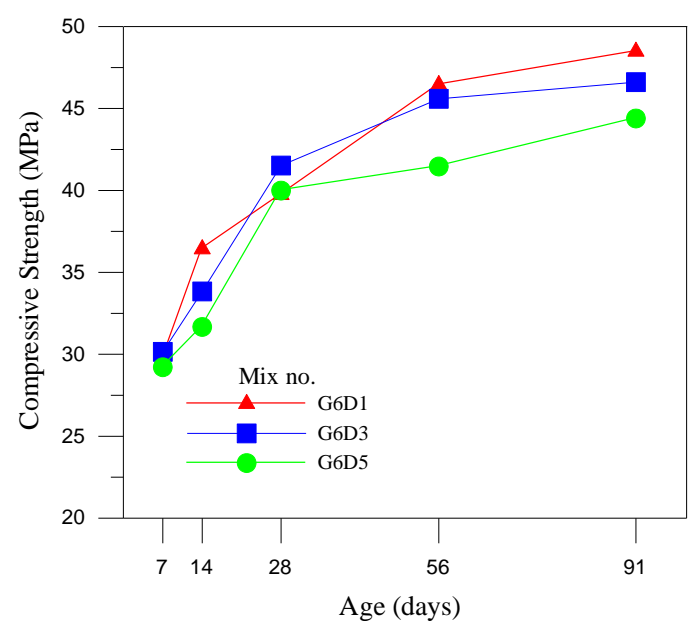

Fig. 4 Compressive strength development curves of G60 specimens

Fig. 4 presents the compressive strength development curves of G60 specimens containing various quantities of desulphurized gypsum. Compressive strength was shown to increase proportionally with curing age and inversely to the proportion of desulphurized gypsum. At a curing age of 7 days, the strength of all three specimens was similar; however, at 28 
days, the compressive strength of the G60D3 specimens was slightly (5\%) higher than that of the other specimens. At 91 days, the G60D1 specimens presented the highest compressive strength. These results indicate that the desulfurized gypsum was weaker than co-fired fly ash in terms of its ability to blend with ggbs.

The compressive strength of all cementless specimens approached the target strength of $30 \mathrm{MPa}$ at 7 days, reaching 40 $\mathrm{MPa}$ at 28 days. At 91 days, the maximum strength in G60D1 specimens reached $48.5 \mathrm{MPa}$ (a 22\% increase from 28 days). This is an indication that in these specimens, the co-fired fly ash and desulfurized gypsum can be regarded as an alkaline excitation material. Following the addition of ggbs, the cementless blended specimens reached the target strength for ternary cementless blended materials. This can be attributed to the reaction of $\mathrm{Ca}(\mathrm{OH})_{2}$ and other hydrated components with water after $\mathrm{CaO}$ hydration. Note that ggbs must be mixed with strongly alkaline materials (e.g., co-fired fly ash) to achieve an activated hydration reaction and corresponding hardening.

Fig. 5 presents compressive strength histograms of G50 specimens containing various quantities of desulfurized gypsum. The compressive strength of specimens with 3\% desulfurized gypsum exceeded that of the other samples at 7, 14, 28, and 56 days. Note that the G50D3 sample achieved compressive strength of $47.4 \mathrm{MPa}$ at 56 days, which far exceeds the typical target strength of conventional Portland (35 MPa) [24, 31-33].

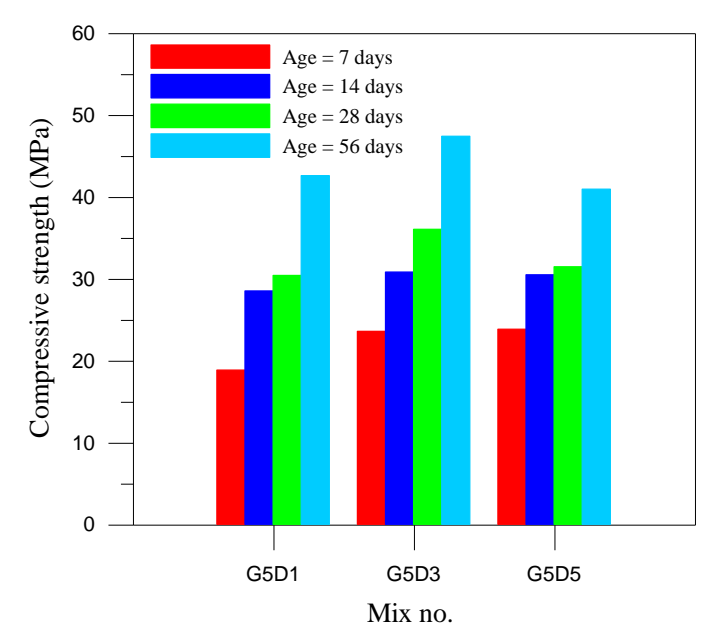

Fig. 5 Compressive strength histograms of G50 specimens

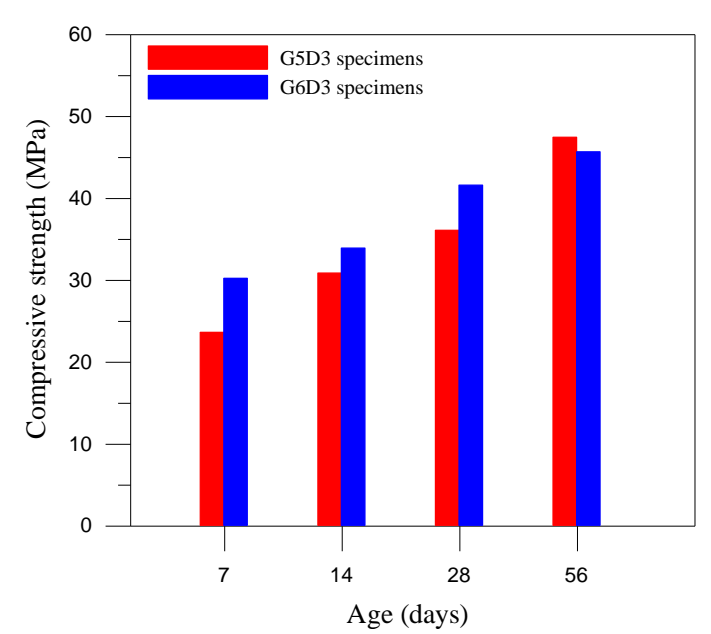

Fig. 6 Compressive strength histograms comparing G50D3 and G60D3 specimens

Fig. 6 presents compressive strength histograms of specimens with a fixed quantity of gypsum (3\%) and either 50\% or $60 \%$ ggbs (G50D3 and G60D3). The compressive strength of G50D3 exceeded that of G60D3 specimens at 7 to 28 days, due to the high proportion of co-fired fly ash. Like conventional fly ash, specimens containing higher proportions of co-fired fly ash achieved the majority of their strength between 28 and 90 days. The retarded hydration reaction associated with the co-fired fly ash caused the molecules to react with water and gain strength at a later stage. Note that the compressive strength of G60D3 specimens exceeded that of G50D3 specimens at 56 days. Thus, engineers should consider the late strength development of composites containing co-fired fly ash and apply them accordingly.

\subsection{Absorption}

Absorption testing is an indirect approach to the evaluation of pore structure and compactness in cementitious materials. The main active components in co-fired fly ash, desulfurized gypsum, and ggbs include $\mathrm{CaO}, \mathrm{SiO}_{2}, \mathrm{Al}_{2} \mathrm{O}_{3}, \mathrm{MgO} \mathrm{As}$ shown in Fig. 7, the absorption of all specimens decreased with curing age. The absorption of G60D1and G60D3 dropped off significantly at 91 days, whereas the absorption of G60D5 began slowing after just 14 days. Increasing the proportion of desulfurized gypsum was shown to reduce the density of the cementless materials through the formation of pores via the expansive formation of ettringite. The formation of ettringite $\left(3 \mathrm{CaO} \cdot \mathrm{Al}_{2} \mathrm{O}_{3} \cdot 3 \mathrm{CaSO}_{4} \cdot 32 \mathrm{H}_{2} \mathrm{O}\right)$ can be attributed to reactions 


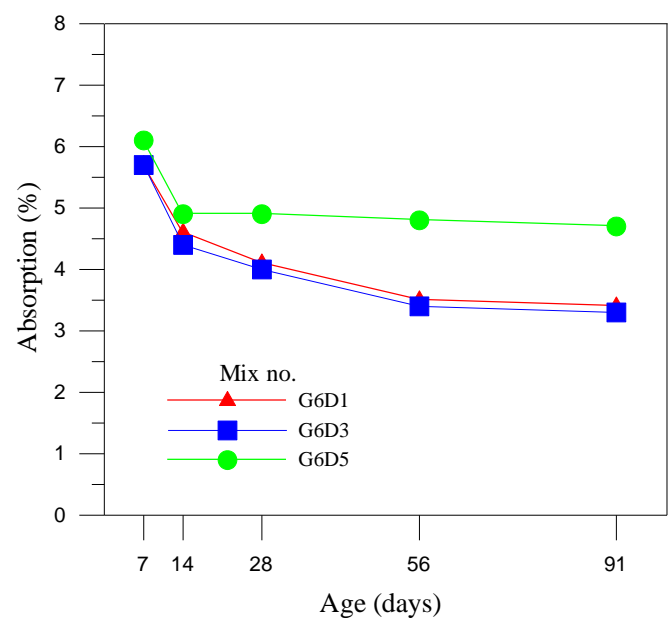

Fig. 7 Absorption of G60 specimens containing various quantities of desulfurized gypsum

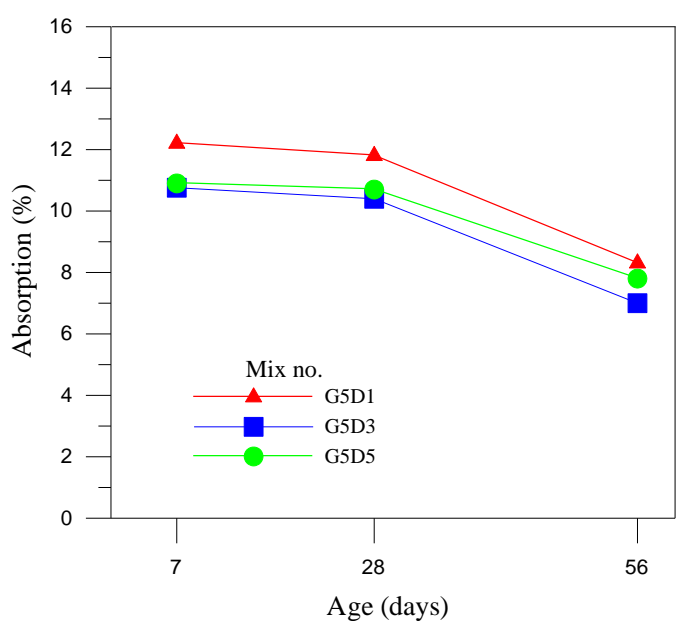

Fig. 8 Absorption of G50 specimens containing various quantities of desulfurized gypsum

between gypsum and calcium aluminate hydrates (e.g., $4 \mathrm{CaO} \cdot \mathrm{Al}_{2} \mathrm{O}_{3} \cdot 13 \mathrm{H}_{2} \mathrm{O}$ ) [34]. However, the different proportions in each group of G50 specimens produced similar results, and the effect of desulfurized gypsum on absorption was not significant, as shown in Fig. 8.

\subsection{Penetration depth of chloride ions and SEM observations}

Fig. 9 presents the results of accelerated chloride ion migration tests of G60 specimens under non-steady-state conditions. All three test mixtures presented low diffusion behavior (penetration depth), and the depth of penetration decreased significantly with an increase in curing age. The initial current measurement of $22 \mathrm{~mA}$ revealed that the inclusion of pozzolanic materials affected electron ionization. The penetration depth of G60D1 specimens was the lowest at 91 days and presented a linear relationship with compressive strength (see Fig. 10). Desulfurized gypsum, co-fired fly ash, and ggbs contain large quantities of aluminum and iron oxides, such as $\mathrm{Al}_{2} \mathrm{O}_{3}$ and $\mathrm{Fe}_{2} \mathrm{O}_{3}$, which react easily with $\mathrm{CaO}$ in the hydration products to form $\mathrm{CaO} \cdot \mathrm{Al}_{2} \mathrm{O}_{3} \cdot \mathrm{Fe}_{2} \mathrm{O}_{3}$. Likewise, reactions of $\mathrm{CaO}$ with $\mathrm{Al}_{2} \mathrm{O}_{3}, \mathrm{Fe}_{2} \mathrm{O}_{3}$, and $\mathrm{H}_{2} \mathrm{O}$ in the hydration products form hydration reactants such as $3 \mathrm{CaO} \cdot \mathrm{Al}_{2} \mathrm{O}_{3} \cdot 10 \mathrm{H}_{2} \mathrm{O}$ or $3 \mathrm{CaO} \cdot \mathrm{Fe}_{2} \mathrm{O}_{3} \cdot 10 \mathrm{H}_{2} \mathrm{O}$, which are key factors in the development of strength in cementitious materials [35-36]. This is likely the main issue reducing the transmission of chloride ions. Fig. 9 presents regression analysis of compressive strength tests and chloride migration tests, showing that chloride ion permeability was negatively correlated with compressive strength and that the relationship was linear.

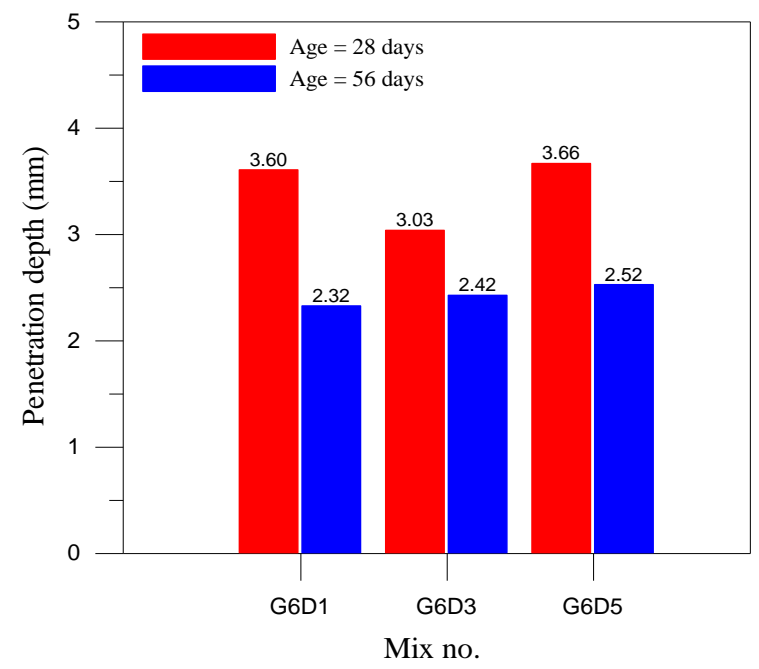

Fig. 9 Penetration depth histograms of G60 specimens

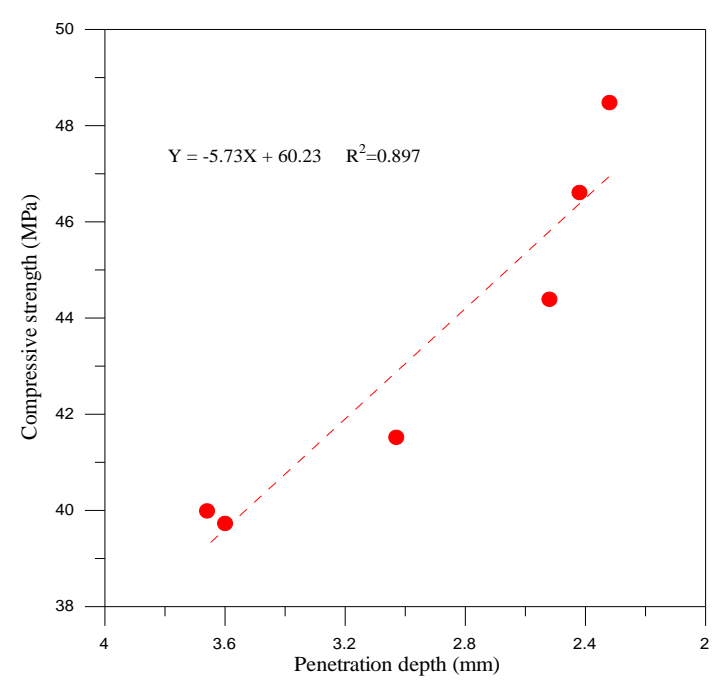

Fig. 10 Compressive strength versus ion penetration depth

The SEM images in Figs. 11-12 show that few of the particles in the G50D1 and G60D1 specimens presented the polygonal shape characteristic of ggbs, indicating that there was insufficient fly ash and ggbs to participate in the hydration 
reaction. The low absorption of the G60D3 and G60D1 specimens can be attributed to the fact that the ggbs particles were covered and most of the pores were filled with C-S-H colloids. The G50D1 specimens presented a small number of needle-shaped ettringite (AFt) and hexagonal flake-shaped or rose petal-shaped monosulfide calcium aluminate (AFm) hydration products. G60D1 specimens presented a large number of needle-shaped ettringite (AFt) and flake-shaped (AFm) hydration products. This is an indication that there was a sufficient quantity of co-fired fly ash and ggbs to produce a complete hydration reaction, which may explain the high compressive strength. Note however, that the large quantities of AFt and AFm had a swelling effect, which left the specimens somewhat porous (i.e, susceptible to absorption and greater penetration depth). The SEM images also revealed needle-like C-S-H particles stacked irregularly on the surface of the gypsum, slag, and co-fired fly ash particles. These results are consistent with those reported in previous studies [23, 26, 31, 37], in which the main hydration products were C-S-H and C-A-S-H gels with high strength development in later curing stages (56 to 91 days).

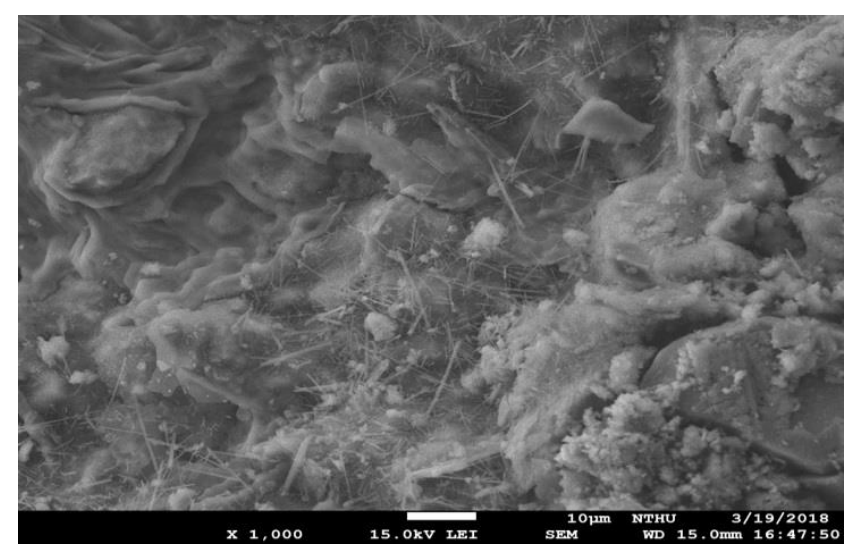

Fig. 11 SEM image of G50D1 specimen (x1000)

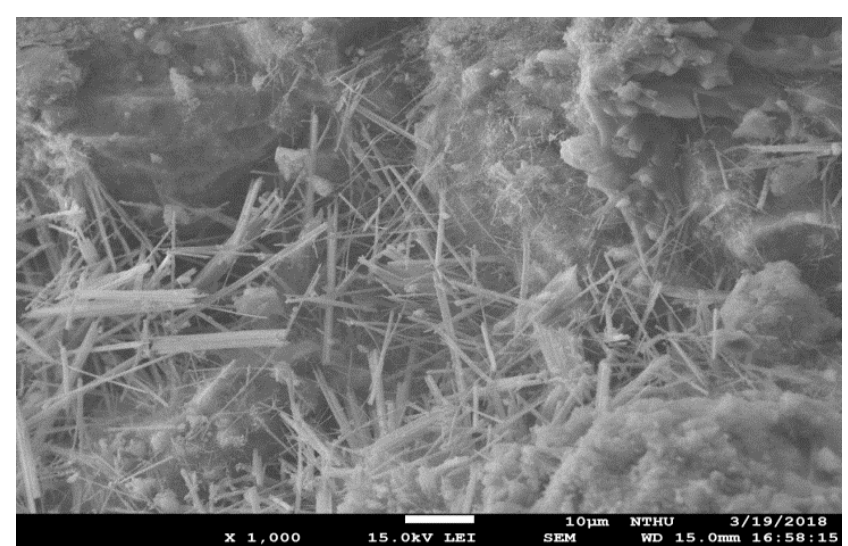

Fig. 12 SEM image of G60D1 specimen (x1000)

\section{Conclusions}

This study examined ternary cementless blended materials without an alkali activator. The engineered properties of the proposed cementless materials meet or exceed those of conventional concrete based on Portland cement. The compressive strength of the G60D1 specimens reached $48.5 \mathrm{MPa}$ at 91 days. The addition of desulfurized gypsum increased the setting time due to the formation of monosulfoaluminate and hydroxy-AFm phase.

It has previously been demonstrated that cementless materials containing ggbs are capable of self-hydration when combined with industrial by-products even in the absence of an alkali activator. It appears that the large quantities of calcium oxide and calcium oxide in co-fired fly ash and desulfurized gypsum met water as hydrogen, resulting in the rupturing and dissolution the glassy ggbs particles. The consumption of calcium hydroxide to produce C-S-H colloid as a hydration product increased the compactness and hardness of the specimens, resulting in strength values comparable to those of cementitious materials. All of the specimens demonstrated extended pozzolanic reactions, which reduced the number of capillary or gel pores as well as the connectivity between pores. The G60D3 specimens presented the highest compressive strength and highest resistance to absorption and chloride ion penetration. An excessive quantity of desulfurized gypsum tended to hinder hydration, which had negative effects on the engineering properties and durability of the resulting cementless materials. These cementless materials could help to reduce carbon dioxide emissions and conserve the consumption of raw materials.

\section{Acknowledgements}

This work was supported by the Ministry of Science and Technology (MOST) under the Grant MOST 108-2221-E-197-006 in Taiwan is gratefully acknowledged. This research was also acknowledged by the Polish National Agency for Academic Exchange under the International Academic Partnership Programme within the framework of the grant: E-mobility and sustainable materials and technologies EMMAT. 


\section{Conflicts of Interest}

The authors declare no conflict of interest.

\section{References}

[1] L. Zhang, C. He, A. Yang, Q. Yang, and J. Han, "Modeling and implication of coal physical input-output table in China-based on clean coal concept," Resources, Conservation and Recycling, vol. 129, pp. 355-365, February 2018.

[2] A. Hasan, M. G. Kibria, and F. M. M. Hasan, "Effects of incorporating recycled brick and stone aggregate as replacement of natural stone aggregate in concrete,” International Journal of Engineering and Technology Innovation, vol. 9, no. 1, pp. 38-48, January 2019.

[3] J. Acordi, A. Luza, D. C. N. Fabris, F. Raupp-Pereira, A. De Noni Jr, and O. R. K. Montedo, "New waste-based supplementary cementitious materials: mortars and concrete formulations," Construction and Building Materials, vol. 240, article 117877, April 2020.

[4] W. T. Lin, "Characterization and permeability of cement-based materials containing calcium fluoride sludge," Construction and Building Materials, vol. 196, pp. 564-573, January 2019.

[5] R. M. Novais, J. Carvalheiras, L. Senff, A. M. Lacasta, I. R. Giro-Paloma, J. Giro-Paloma, et al., "Multifunctional cork alkali-activated fly ash composites: a sustainable material to enhance buildings' energy and acoustic performance," Energy and Buildings, vol. 210, article 109739, March 2020.

[6] N. Cristelo, J. Coelho, T. Miranda, Á. Palomo, and A. Fernández-Jiménez, “Alkali activated composites - an innovative concept using iron and steel slag as both precursor and aggregate," Cement and Concrete Composites, vol. 103, pp. 11-21, October 2019.

[7] C. C. Hung, Y. C. Wu, W. T. Lin, J. J. Chang, and W. C. Yeih, "Effect of mixture variables on durability for alkali-activated slag cementitious," Materials, vol. 11, no. 11, article 2252, November 2018.

[8] S. S. S. A. Nedunuri, S. G. Sertse, and S. Muhammad, "Microstructural study of portland cement partially replaced with fly ash, ground granulated blast furnace slag and silica fume as determined by pozzolanic activity," Construction and Building Materials, vol. 238, article 117561, March 2020.

[9] M. J. Moghadam, R. Ajalloeian, and A. Hajiannia, "Preparation and application of alkali-activated materials based on waste glass and coal gangue: a review," Construction and Building Materials, vol. 221, pp. 84-98, October 2019.

[10] T. Luukkonen, Z. Abdollahnejad, J. Yliniemi, M. Mastali, P. Kinnunen, and M. Illikainen, "Alkali-activated soapstone waste - mechanical properties, durability, and economic prospects," Sustainable Materials and Technologies, vol. 22, article e00118, December 2019.

[11] P. Awoyera and A. Adesina, "A critical review on application of alkali activated slag as a sustainable composite binder," Case Studies in Construction Materials, vol. 11, article e00268, December 2019.

[12] S. Luhar, T. W. Cheng, D. Nicolaides, I. Luhar, D. Panias, and K. Sakkas "Valorisation of glass wastes for the development of geopolymer composites - durability, thermal and microstructural properties: a review," Construction and Building Materials, vol. 222, pp. 673-687, October 2019.

[13] S. Badur and R. Chaudhary, "Utilization of hazardous wastes and by-products as a green concrete material through S/S process: a review," Reviews on Advanced Materials Science, vol. 17, no. 1-2, pp. 42-61, 2008.

[14] P. Asokan, M. Saxena, and S. R. Asolekar, "Hazardous jarosite use in developing non-hazardous product for engineering application,” vol. 137, no. 3, pp.1589-1599, October 2006.

[15] A. A. Kadir, M. I. H. Hassan, and M. M. A. B. Abdullah, "Investigation on leaching behaviour of fly ash and bottom ash replacement in self-compacting concrete," IOP Conference Series: Materials Science and Engineering, vol. 133, no. 1, p. 012036, June 2016.

[16] A. A. Kadir, H. Hermawati, and A. S. Noor, "The utilization of coffee waste into fired clay brick," ARPN Journal of Engineering and Applied Sciences, vol. 10, no. 15, pp. 6289-6292, 2015.

[17] M. P Mubiayi, M. E Makhatha, and E. T Akinlabi, "Characterization, leachate characteristics and compressive strength of jarosite/clay/fly ash bricks,” Materials Today: Proceedings, vol. 5, no. 9, pp.17802-17811, 2018.

[18] M. Katsioti, O. Mauridou, A. Moropoulou, E. Aggelakopoulou, P. E. Tsakiridis, S. Agatzini-Leonardou, et al., "Utilization of jarosite/alunite residue for mortars restoration production," Materials and Structures, vol. 43, no. 1-2, pp.167-177, 2010.

[19] A. A. Phul, M. J. Memon, S. N. R. Shah, and A. R. Sandhu, "GGBS and fly ash effects on compressive strength by partial replacement of cement concrete," Civil Engineering Journal, vol. 5, no. 4, pp. 913-921, 2019. 
[20] A. M. Shihab, J. M. Abbas, and A. M. Ibrahim, "Effects of temperature in different initial duration time for soft clay stabilized by fly ash based geopolymer," Civil Engineering Journal, vol. 4, no. 9, pp. 2082-2096, 2018.

[21] W. Zhang, H. Choi, T. Sagawa, and Y. Hama, "Compressive strength development and durability of an environmental load-reduction material manufactured using circulating fluidized bed ash and blast-furnace slag," Construction and Building Materials, vol. 146, pp. 102-113, August 2017.

[22] H. A. Nguyen, T. P. Chang, J. W. Shih, C. T. Chen, and T. D. Nguyen, "Influence of circulating fluidized bed combustion (CFBC) fly ash on properties of modified high volume low calcium fly ash (HVFA) cement past," Construction and Building Materials, vol. 91, pp. 208-215, August 2015.

[23] M. Chi, "Synthesis and characterization of mortars with circulating fluidized bed combustion fly ash and ground granulated blast-furnace slag," Construction and Building Materials, vol. 123, pp. 565-573, October 2016.

[24] Y. H. Wu, R. Huang, C. J. Tsai, and W.T. Lin, "Utilizing residues of CFB co-combustion of coal, sludge and TDF as an alkali activator in eco-binder," Construction and Building Materials, vol. 80, pp. 69-75, April 2015.

[25] T. M. Do, G. Kang, and Y. Kim, "Development of a new cementless binder for controlled low strength material (CLSM) using entirely by-products," Construction and Building Materials, vol.206, pp. 576-589, May 2019.

[26] H. L. Ho, R. Huang, L. C. Hwang, W. T. Lin, and H. M. Hsu. "Waste-based pervious concrete for climate-resilient pavements," Materials, vol. 11, no. 6, article 900, May 2018.

[27] M. Chi and R. Huang, "Effect of circulating fluidized bed combustion ash on the properties of roller compacted concrete," Cement and Concrete Composites, vol. 45, pp. 148-156, January 2014.

[28] W. T. Lin, K. L. Lin, K. Chen, K. Korniejenko, M. Hebda, and M. Łach, "Circulation fluidized bed combustion fly ash as partial replacement of fine aggregates in roller compacted concrete,” Materials, vol. 12, no. 24, article 4208, December 2019.

[29] A. Quennoz and K. L. Scrivener, "Hydration of $C_{3}$ A-gypsum systems," Cement and Concrete Research, vol. 42, no. 7, pp. 1032-1041, July 2012.

[30] M. C. Caillahua and F. J. Moura, "Technical feasibility for use of FGD gypsum as an additive setting time retarder for Portland cement,” Journal of Materials Research and Technology, vol. 7, no. 2, pp. 190-197, April-June 2018.

[31] W. T. Lin, K. L. Lin, K. Korniejenko, L. Fiala, A. Cheng, and J. Chen, "Composite properties of non-cement blended fiber composites without alkali activator," Materials, vol. 13, no. 6, article 1443, March 2020.

[32] V. Kočí, M. Petříková, J. Fořt, L. Fiala, and R. Černý, "Preparation of self-heating alkali-activated materials using industrial waste products," Journal of Cleaner Production, vol. 260, article 121116, July 2020.

[33] M. Inoue, H. Choi, and Y. Sudoh, "Fresh properties and strength development of cement mortar using nitrite-based accelerator and chemical admixtures," Proceedings of Engineering and Technology Innovation, vol. 9, pp. 9-16, July 2018.

[34] S. Wansom, P. Chintasongkro, and W. Srijampan, "Water resistant blended cements containing flue-gas desulfurization gypsum, Portland cement and fly ash for structural applications," Cement and Concrete Composites, vol. 103, pp. 134-148, October 2019.

[35] E. J. Anthony, L. Jia, and Y. Wu, “CFBC ash hydration studies,” Fuel, vol. 84, no. 11, pp. 1393-1397, August 2005.

[36] K. L. Lin, T. W. Cheng, C. H. Ho, Y. M. Chang, and K. W. Lo, "Utilization of circulating fluidized bed fly ash as pozzolanic material,” The Open Civil Engineering Journal, vol. 11, no. 1, pp. 176-186, 2017.

[37] C. Baek, J. Seo, M. Choi, J. Cho, J. Ahn, and K. Cho, "Utilization of CFBC fly ash as a binder to produce in-furnace desulfurization sorbent," Sustainability, vol. 10, no. 12, article 4854, December 2018.

Copyright $($ by the authors. Licensee TAETI, Taiwan. This article is an open access article distributed under the terms and conditions of the Creative Commons Attribution (CC BY-NC) license (https://creativecommons.org/licenses/by-nc/4.0/). 